\title{
Testing of Hungarian aggregates for railway ballast according to MSZ EN 13450: 2003
}

\author{
Miklós Gálos, László Kárpáti \\ Department of Construction Materials and Engineering Geology, \\ Budapest University of Technology and Economics, Budapest
}

In June 2003 Hungary accepted the European Standard for Aggregates for Railway Ballast (MSZ EN 13450: 2003). The European norm, compared with the Hungarian Standard, also includes a new examination method called the micro-Deval method for railway ballast aggregates, which was previously not used in Hungary. This paper presents the test results of aggregates for railway ballastproducing quarries, according to newly accepted Standard. The test materials consist of andesite, basalt, dolomite and limestone. The results cover a significant range. The study was aimed at finding a relation between the testing methods, in order to reduce the testing procedure; however, no clear relationship was found.

Key words: aggregates, Los Angeles tests, micro-Deval tests, railway ballast

\section{Introduction}

Aggregates are the most common building materials. A significant amount of coarse and fine aggregates is used in building construction as well as for roads, highways, bridges, and railways. The application of the raw material depends on its physical properties, especially durability and abrasion resistance. Previous work dealt with the testing of various properties, including abrasion resistance, by using the Los Angeles method (Kahraman and Gunaydin 2007) Kahraman and Fener (2007) tried to correlate Los Angeles abrasion resistance to uniaxial compressive strength. The new European Standard for Aggregates for Railway Ballast (EN 13450: 2002) contains, beside the Los Angeles system, a new exami-

Addresses: M. Gálos, L. Kárpáti: H-1111 Budapest, Stoczek u. 2, Hungary, e-mail:m.galos@freemail.hu,karpati.laci@gmail.com

Received: January 2, 2008; accepted: February 4, 2008 
nation method for railway ballast, the micro-Deval method, which requires new test equipment. The first such device in Hungary was obtained by the Laboratory of the Department of Construction Materials and Engineering Geology. Hungarian aggregates from 11 different railway ballast-producing quarries were tested: Abasár, Komló, Nógrádkövesd, Recsk, Szob, Tállya, Zsunypuszta, Bazsi, Uzsa, Bükkösd, and Iszkaszentgyörgy (Fig. 1). Aggregates taken directly from railway beds were also tested: samples were taken from 8 different active railway lines throughout Hungary. The tested railroad lines and the age ranges of their ballast were the Cegléd-Abony ( $0-5$ years), Mezôtúr- Csugar ( $0-5$ years), Nagyrákos (5-10 years), Pankasz (5-10 years), Zalalövő (5-10 years), Városföld (10-15 years), Kimle-Mosonmagyaróvár (10-15 years), and Siófok-Kaposvár (10-15 years) sections. Four types of laboratory experiments were carried out for each sample according to MSZ EN 13450: 2003. These included the determination of particle size distribution (sieving method), determination of shape index, the determination of the resistance to wear (micro-Deval resistance) and the determination of the resistance to fragmentation (Los Angeles resistance). Los Angeles and micro-Deval values for 65 test material samples were obtained. The test results aim to characterize the Hungarian aggregates for railway ballast according to MSZ EN 13450: 2003.

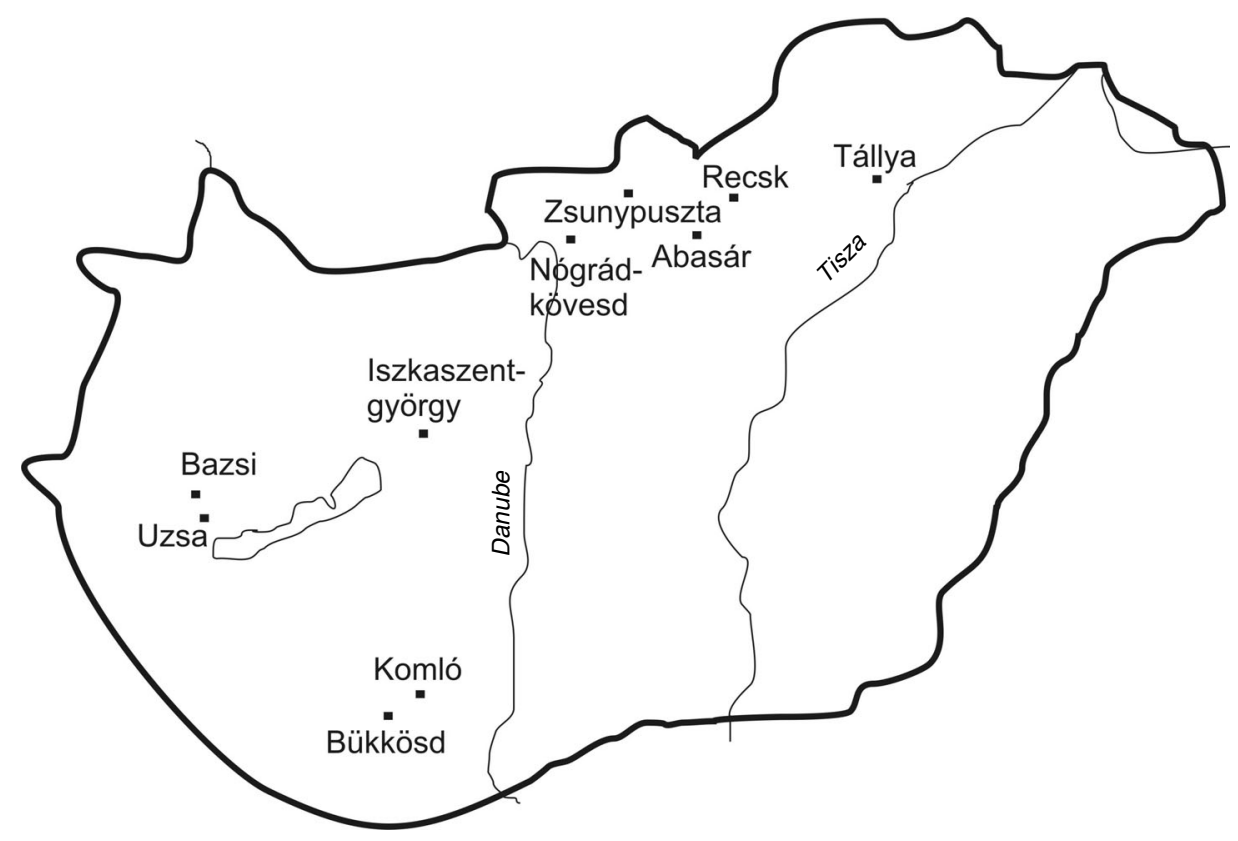

Fig. 1

Location of the quarries in Hungary that provided aggregates for the tests 


\section{Materials}

The tested rock material included andesite, basalt, dolomite and compact limestone. The andesite from Komló (Fig. 2) is gray or dark gray, finegrained amphibole andesite with a porphyritic fabric. The basalt from Uzsa (Fig. 3) is gray or dark gray, finegrained volcanic rock, also with porphyritic fabric. Various andesites are observable in Szob: dark gray, coarse-grained amphibole andesite,

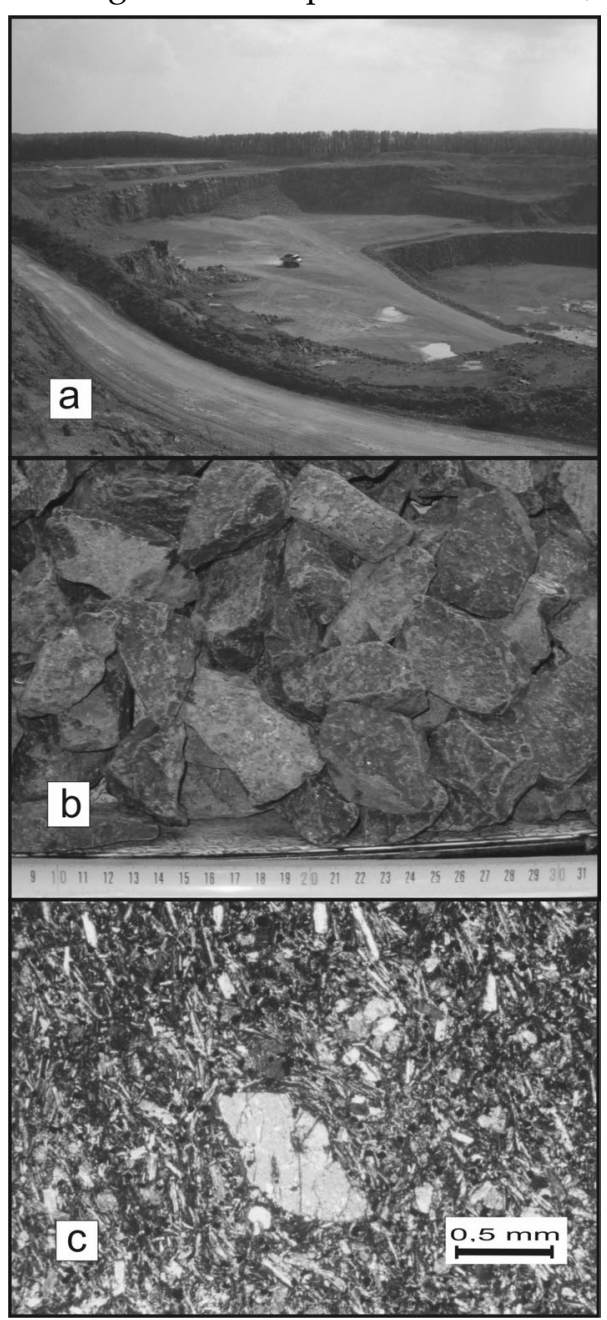

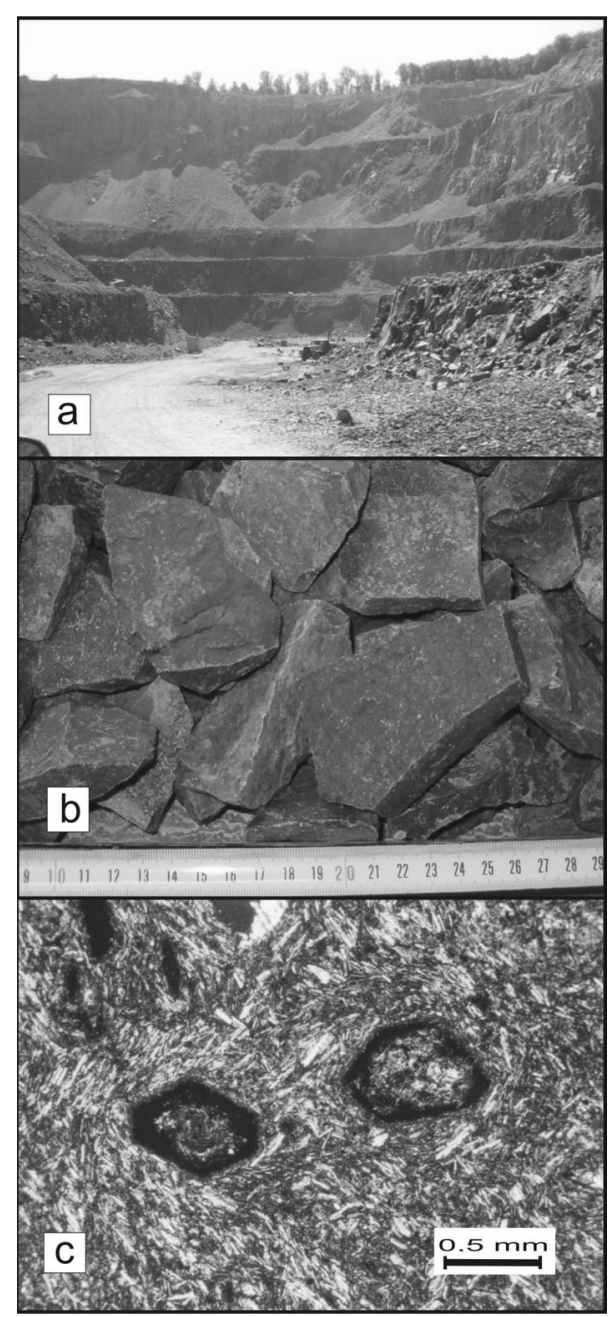

Fig. 2

Andesite from Komló: (a) quarry, (b) andesite aggregate, (c) microscopic image of amphibole andesite

$\leftarrow$ Fig. 3

Basalt from Uzsa: (a) quarry (b) basalt aggregate, (c) microscopic image of olivine basalt 
light gray, fine-grained amphibole andesite and light gray amphibole dacite with biotite. A pyroxene andesite from Nódrádkövesd was also analyzed. The andesite from Zsunypuszta is dark gray, somewhere brownish pyroxene andesite with porphyritic fabric. The andesite from Recsk (Fig. 4) is of medium gray to reddishbrown color. Dark gray, rigid pyroxene andesite from Tállya (Fig. 5) was also measured in the course of the tests. Dolomite from Iszkaszentgyörgy is grayishwhite, compact, and fine-grained. Brownish-gray compact limestone from Bükkösd was also tested (Emszt 2006).

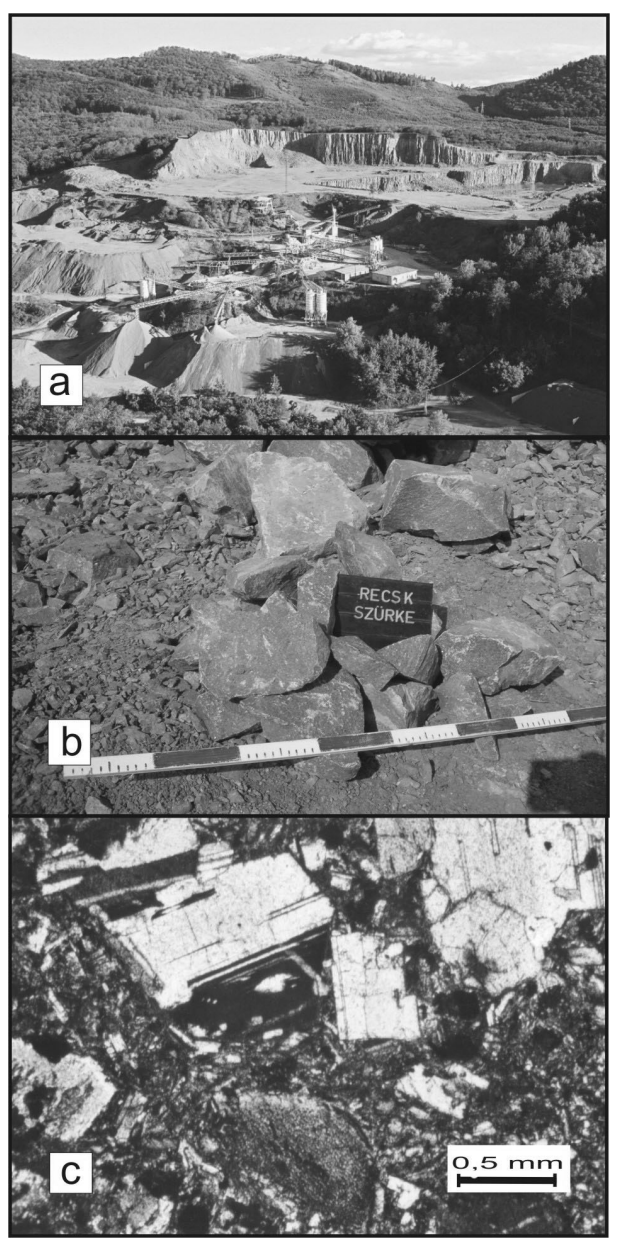

Fig. 4

Andesite from Recsk: (a) quarry, (b) andesite aggregate, (c) microscopic image of large plagioclase crystals

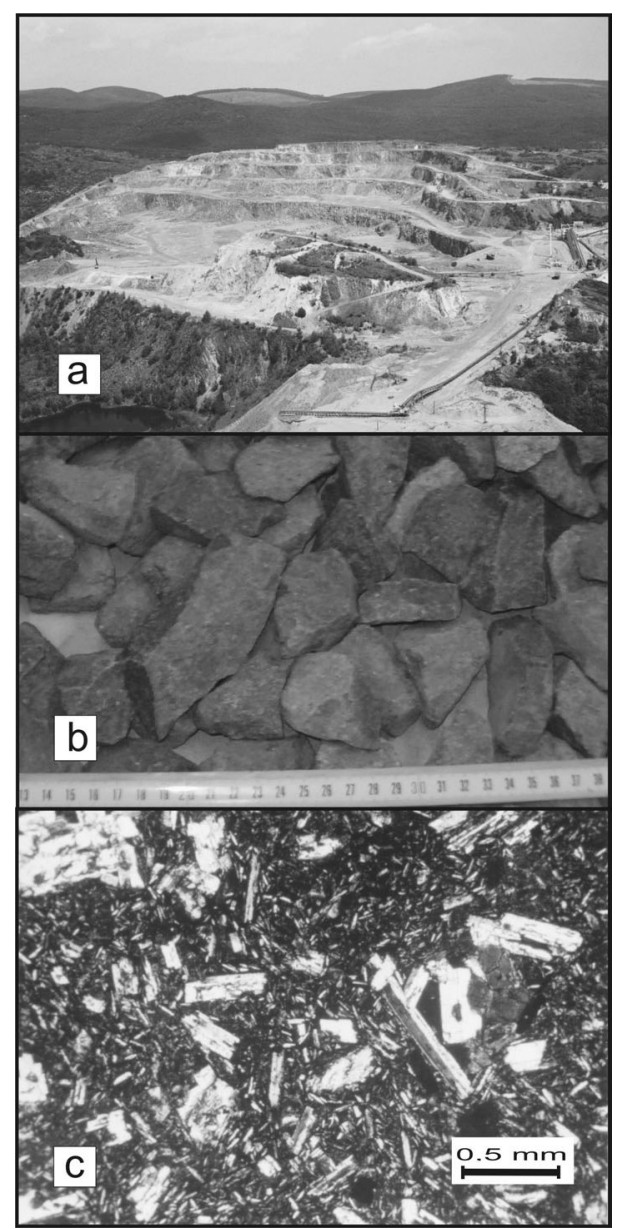

Fig. 5

Andesite from Tállya: (a) quarry, (b) andesite aggregate, (c) microscopic image of needleshaped plagioclase crystals 


\section{Methods}

The rock properties depend upon the procedure of the rock genesis, mineral composition, the binding strength between the rock matrix, and the subsequent effects on the rock itself; in short, it depends on the petrologic properties. These can be given in a descriptive fashion only, but in civil engineering practice, property characteristics which can be evaluated on the basis of test results, with accompanying values and functional connections, are required.

Among the measurable petrophysical properties, strength properties of the aggregates play an important role in the qualification practice. Evaluating this is similar to the testing method of the uniaxial compressive strength for building stone, which is used to determine their compressive strength.

Tests with revolving drums (Los Angeles and micro-Deval tests) of aggregates used as railway ballast serve to determine the deformations caused by dynamic load resulting from vehicle traffic. During the petrophysical tests conducted in laboratories the rock material is emplaced in a revolving drum, where the particles are crushed during the rotating movement, as a result of friction and bumping into the wall of the drum. Additionally, steel balls as abrasive filling increase fragmentation and wearing of the particles (Gálos and Kárpáti 2007).

Resistance to fragmentation (Los Angeles test) for railway ballast was determined according to MSZ EN 13450: 2003. It requires about 10,000 g of test material and 12 steel balls of a total mass of nearly 5,210 g. The typical device for the Los Angeles (LA) test is shown in Fig. 6. The LA test should be performed in a revolving drum with a diameter of $711 \mathrm{~mm}$, where stress will be ensured by the

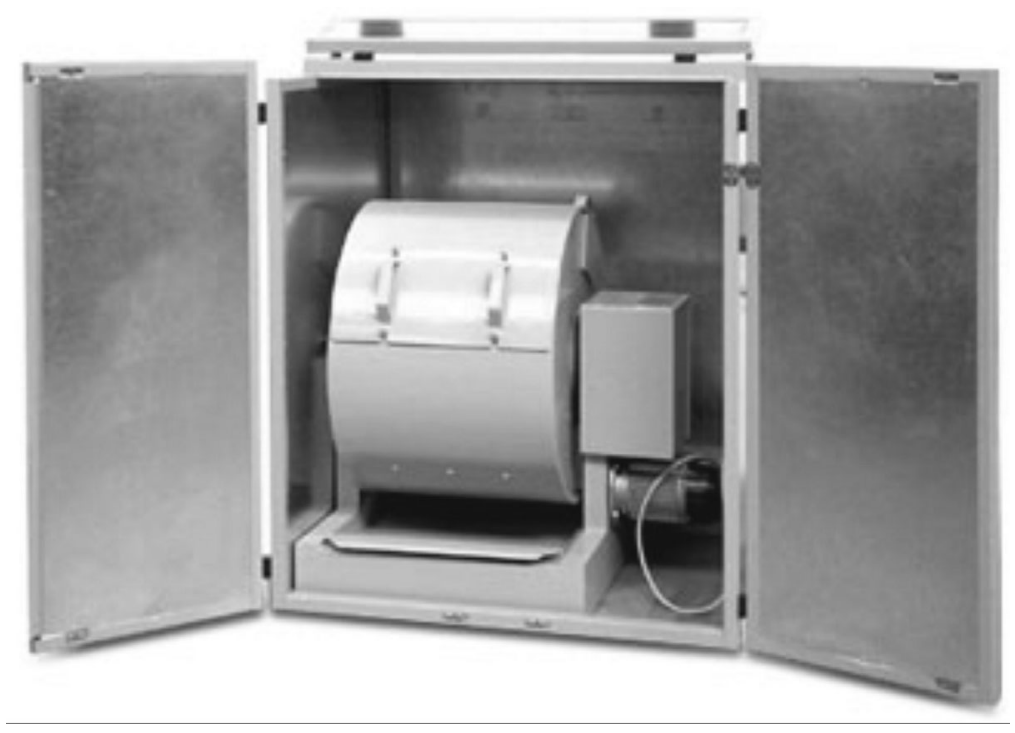

Fig. 6

Los Angeles test equipment 
steel balls (with a diameter of $45-49 \mathrm{~mm}$ ) falling past the partition plate into the revolving drum among the rock material, as well as the friction on the inner surface of the drum. The test procedure is as follows: the total dried test material, which consists of the combination of given aggregate fraction sizes and steel balls, is emplaced in the drum, which rotates for 1000 revolutions at a rate of 31 33 rotations/minute. The aggregate is then passed over a test sieve of $1.6 \mathrm{~mm}$ mesh and washed by a clean water-jet. The total dried mass of the material retained by the $1.6 \mathrm{~mm}$-mesh sieve is measured and recorded. The LA test gives a bulk index value according to the following equation:

$$
L A_{R B}=\frac{10000-m}{100}
$$

where

$m$ : is the mass of the material retained on the $1.6 \mathrm{~mm}$-mesh sieve, grams.

The resistance to wear (micro-Deval test) for railway ballast aggregates was determined according to MSZ EN 13450: 2003. The device for the micro-Deval test is shown in Fig. 7. The test is carried out with this system, which has drum with an internal length of about $400 \mathrm{~mm}$. No abrasive charge (steel balls) is required. Given size fractions are combined to produce a test specimen with total dry mass of about $10,000 \mathrm{~g}$. Two liters of water are added to each drum, which rotates for 14,000 revolutions at a rate of $95-105$ rotations/minute. The test material is then passed over a test sieve of $1.6 \mathrm{~mm}$-mesh and washed by a clean water-jet. The total dried mass of the material retained on the $1.6 \mathrm{~mm}$-mesh sieve

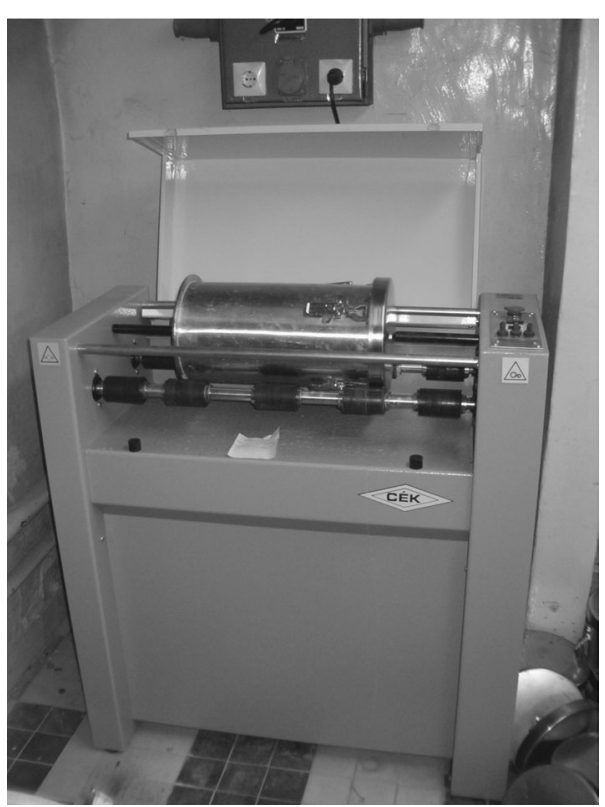
is measured and recorded. The microDeval test gives a bulk index value according to the following equation (Árpás et al. 2006):

$$
M_{D E} R B=\frac{10000-m}{100}
$$

where

$m$ : is the mass of the material retained on the $1.6 \mathrm{~mm}$-mesh sieve, in grams.

\section{Results}

Following the Los Angeles test, sharp chips were broken off the edges of the specimens, while after the micro-Deval test the specimens became rounded

Fig. 7

Micro-Deval test equipment 
(Figs 8,9 ). The same process of alteration could be observed on all of the tested rock material (andesite, basalt, dolomite, and limestone). The Los Angeles test method transmits a great dynamic load during the revolutions; therefore the samples broke immediately, causing the sharp, broken surface. The micro-Deval test procedure has a greater abrasive effect on rock; thus the samples became rounded. Some rock material reacts more sensitively in the presence of water; therefore more tests are planned to analyze the effect of water.

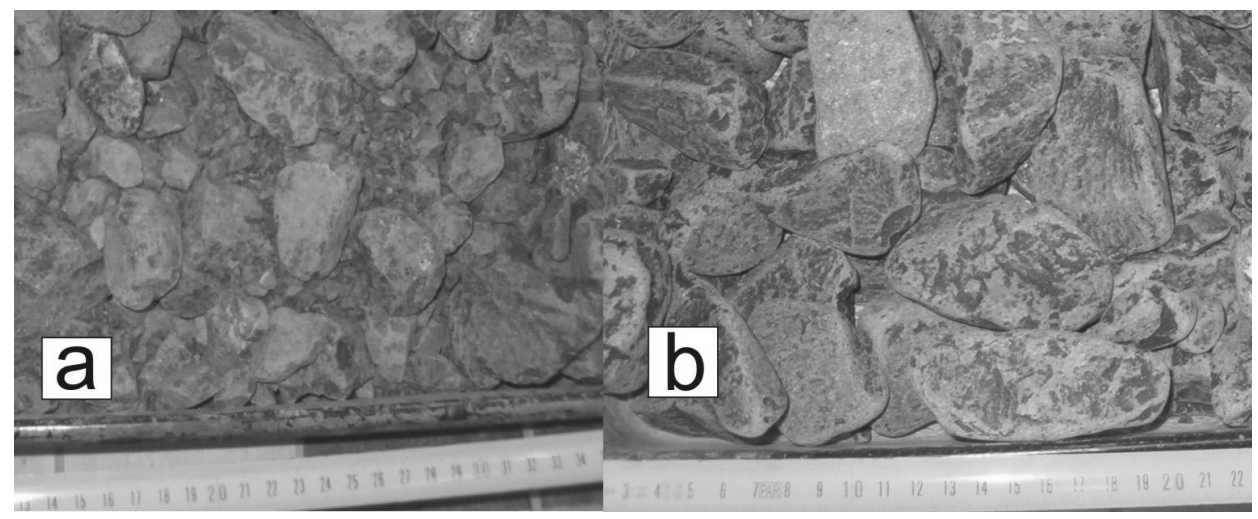

Fig. 8

The basalt from Uzsa after Los Angeles test (a) and micro-Deval test (b)

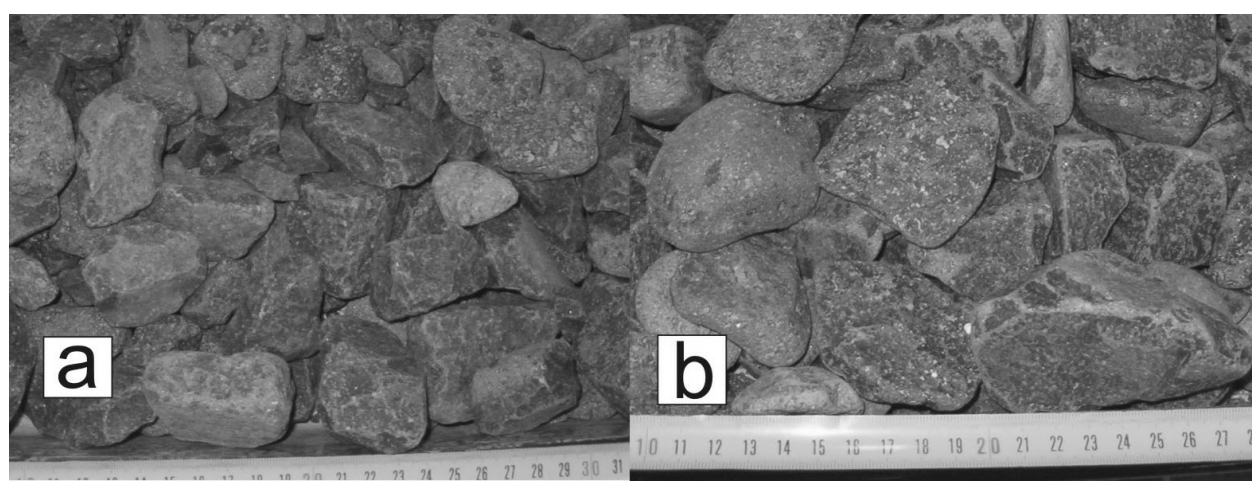

Fig. 9

The andesite from Tállya after Los Angeles test (a) and micro-Deval test (b)

Figure 10 shows the results of Los Angeles and micro-Deval tests. It was attempted to analyze a relationship between the results of the two testing method, but no clear connection was discovered (Gálos et al. 2006). According to our tests the Hungarian ballast material shows significant variability. The limestone samples from Bükkösd are not shown in Fig. 10 because of its LA 
results; this limestone has weak resistance to dynamic effects. It is remarkable that the dolomite from Iszkaszentgyörgy shows better results than some andesite samples. The test material taken directly from railway beds show almost the same resistance to fragmentation and wear as the samples from the producing quarries.

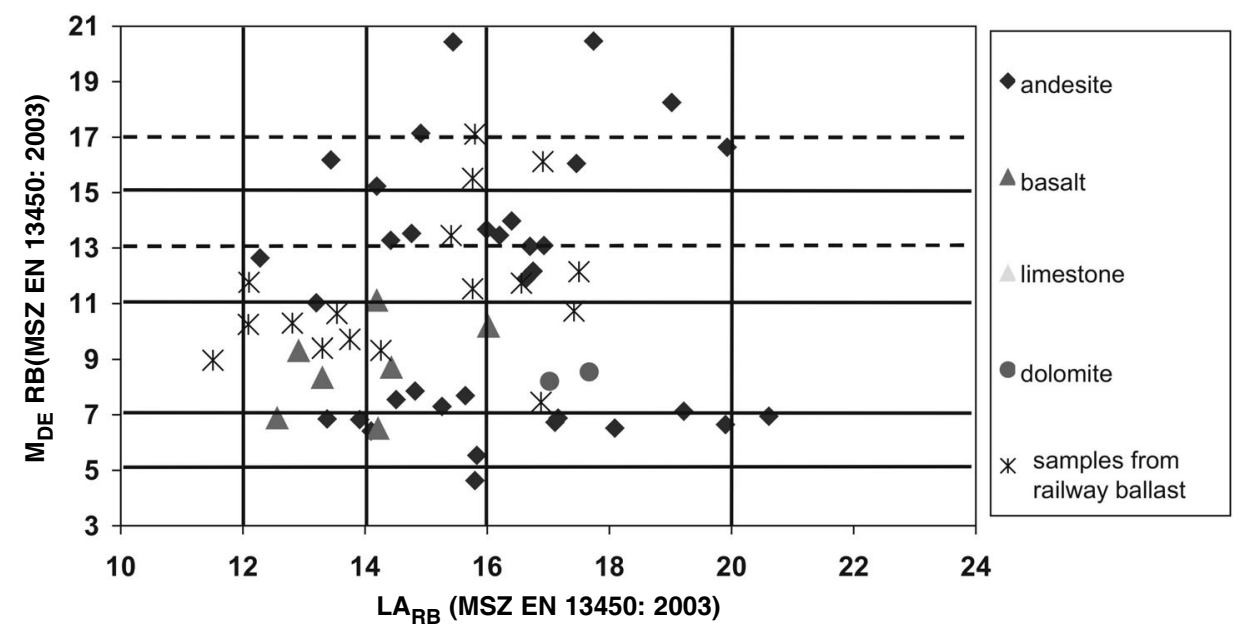

Fig. 10

Results of Los Angeles and micro-Deval tests

\section{Conclusions}

There is no unequivocal relationship between resistance to fragmentation (Los Angeles test) and wear (micro-Deval test); therefore both of these laboratory experiments are required to characterize aggregates for railway ballast.

Beside resistance to fragmentation and wear, durability and resistance to weathering are also important factors in judging the quality of the aggregates. Further research work will also include freeze-thaw and magnesium-sulfate crystallizing tests, as well as computer simulation tests following Lim and McDowell (2005).

The test results cover a large range; therefore it is necessary to check the aggregate quality and apply the proper railway ballast based on the maximum speed to be attained on any given railway line. 


\section{Acknowledgements}

The new micro-Deval device was purchased with the support of ColasÉszakkő Bányászati Kft. We are also very grateful to the Hungarian State Railways which financially supported our experiment. We thank I. Türk and D. Szekeres for comments and suggestions. The laboratory work and help of Gy. Emszt and E. Árpás are appreciated.

\section{References}

Árpás, E., Gy. Emszt, M. Gálos, L. Kárpáti 2006: Methodology of micro-Deval test for aggregates for railway ballast. - Építóanyagok, 58/3, pp. 92-96. (In Hungarian.)

Emszt, Gy. 2006: Testing and standardization of Hungarian aggregates for railway ballast. - BSc thesis, BME. (In Hungarian.)

Gálos, M., L. Kárpáti, Gy. Emszt, E. Árpás 2006: Determination of strength parameters of aggregates for railway ballast according to EN 13450:2002. - Research report, BME, No. 30713-003-MG025/2005. (In Hungarian.)

Gálos, M., L. Kárpáti 2007: Experience about examination of aggregates for railway ballast. - 11th International Conference of Civil Engineering and Architecture, Csíksomlyó, pp. 86-90. (In Hungarian.)

Kahraman, S., M. Fener 2007: Predicting the Los Angeles abrasion loss of rock aggregates from the uniaxial compressive strength. - Materials Letters, 61, pp. 4861-4865.

Kahraman, S., O. Gunaydin 2007: Empirical methods to predict the abrasion resistance of rock aggregates. - Bulletin of Engineering Geology and the Environment, 66, pp. 449-455.

Lim, W.L., G.R. McDowell 2005: Discrete element modelling of railway ballast. - Granular Matter, 7, pp. 19-29. 